\title{
ECOLOGICAL-COENOTIC CONFINEMENT AND RESOURCES CHARACTERISTICS OF ARCTOSTAPHYLOS UVA-URSI (L.) SPRENG. IN KIROV REGION
}

(C) 2018

Luginina Ecaterina Andreevna, researcher of Ecology and Plant Resources Department; assistant of Ecology and Zoology Department

Egoshina Tatiana Leonidovna, doctor of biological sciences, professor,

chief researcher of Ecology and Plant Resources Department; professor of Ecology and Zoology Department Professor Zhitkov Russian Research Institute of Game Management and Fur Farming (Kirov, Russian Federation); Vyatka State Agricultural Academy (Kirov, Russian Federation)

Abstract. The paper presents data on phytocoenotic confinement and resource parameters of Arctostaphylos uvaursi in Kirov Region. The species is close to phytocoenotic optimum in pine herbaceous-lichen forests in coniferousbroadleaved forests sub zone. The highest productivity of $A$. uva-ursi coenopopulations is marked in pine hebaceouslichen forests $\left(56,1 \pm 4,2 \mathrm{~g} / \mathrm{m}^{2}\right)$ where the species has maximum coverage $(16,8 \pm 1,1 \%)$ and shoot length $(17,7 \pm 0,8$ $\mathrm{cm}$ ). Presence of A. uva-ursi in communities increases southwards within the Region. A. uva-ursi is restricted to sandy and sabulous soils with high acidity level ( $\mathrm{pH} 3,4-4,0)$, humus poor and insignificant content of phosphorus, potassium, calcium and magnesium. Reliable relation $(\mathrm{p}<0,05)$ between A. uva-ursi leaves productivity and $\mathrm{Mg}$ content in soil $(\mathrm{r}=0,85)$ was defined. We have also determined straight and reliable connection between coverage, shoots number and productivity $\left(\mathrm{R}^{2}=0,71-0,97\right)$. Raw material productivity can be presented by regression equation: $\mathrm{P}=\mathrm{Ao}+\mathrm{A} 1 \mathrm{C}+\mathrm{A} 2 \mathrm{~N}$, где: $\mathrm{P}$ - Productivity (raw weight, $\mathrm{g} / \mathrm{m}^{2}$ ), $\mathrm{C}$ - coverage $(\%), \mathrm{N}-$ number of shoot (per $\mathrm{m}^{2}$ ). Biological stock (BS) of A. uva-ursi in Kirov Region reaches 285,5 t. Distribution of BS among vegetative subzones and administrative regions is uneven: $51 \%$ of $\mathrm{BS}(144,7 \mathrm{t})$ is concentrated in middle taiga subzone. Exploitation stock (ES) in the Region reaches 109,1 t. Volume of possible annual collection - 7,9 t, which is enough for local needs. In lichen pine forests with areas of $A$. uva-ursi in Kirov Region when $75 \%$ of peripheral shoots are cut, it does not recover within 5-years period between collections.

Keywords: Arctostaphylos uva-ursi; phytocoenotic confinement; phytocoenotic optimum; coenorange; productivity; coverage; biological stock; exploitation stock; volume of possible annual collection; exploitation press; Kirov Region.

УДК 581.5

Статья поступила в редакцию 30.12.2017

\section{ТАКСОНОМИЧЕСКАЯ И БИОМОРФОЛОГИЧЕСКАЯ СТРУКТУРА ФЛОРЫ СОСУДИСТЫХ РАСТЕНИЙ ГОРЫ КУЗНЕЦОВА (САМАРСКАЯ ОБЛАСТЬ, ВОЛЖСКИЙ РАЙОН)}

(C) 2018

Макарова Юлия Владимировна, кандидат биологических наук, старший преподаватель кафедры экологии, ботаники и охраны природы Самарский национальный исследовательский университет имени академика С.П. Королёва (2. Самара, Российская Федерация)

Головлёв Алексей Алексеевич, доктор географических наук, профессор кафедры мировой экономики Самарский государственный экономический университет (2. Самара, Российская Федерация)

Прохорова Наталья Владимировна, доктор биологических наук, профессор кафедры экологии, ботаники и охраны природы Самарский национальный исследовательский университет имени академика С.П. Королёва (2. Самара, Российская Федераџия)

Аннотация. На горе Кузнецова установлено произрастание 267 видов сосудистых растений из 190 родов, 63 семейств, 26 порядков, 4 классов (Equisetopsida, Polypodiopsida, Pinopsida, Angiospermae) и 3 отделов (Еquisetophyta, Polypodiophyta, Spermatophyta). Абсолютное большинство видов относится к отделу Spermatophyta (258 видов, 96,7\%), классу Angiospermae (257 видов, 96,3\%), группе Dicotyledones (228 видов, 85,4\%). Сосудистые споровые растения представлены 9 видами, принадлежащими к 6 родам (Equisetum, Matteuccia, Athyrium, Cystopteris, Dryopteris, Pteridium), 5 семействам (Equisetaceae, Onocleaceae, Woodsiaceae, Dryopteridaceae, Dennstaedtiaceae), 2 классам (Equisetopsida, Polypodiopsida) и 2 отделам (Equisetophyta, Polypodiophyta). Ведущими по числу видов являются семейства Compositae (44 вида, 16,5\%), Leguminosae (22 вида, $8,2 \%$ ) и Rosaceae (18 видов, 6,7\%). Ведущими по числу родов - семейства Compositae (29 родов, 15,3\%), Rosaceae (14 родов, 7,4\%) и Labiatae (13 родов, 6,8\%). Наибольшее число видов сосредоточено в родах Trifolium (7 видов), Viola, Campanula, Galium и Carex (по 4 вида). По системе климаморф К. Раункиера во флоре доминируют гемикриптофиты (148 видов, 55,4\%). По системе биоморф И.Г. Серебрякова и Т.И. Серебряковой - поликарпические короткокорневищные, длиннокорневищные и стержнекорневые травы (47,0\%). Вегетативно неподвижными и малоподвижными являются 76,8\% видов.

Ключевые слова: флора; сосудистые растения; таксономический анализ; биоморфологический анализ; жизненная форма растения; биоморфа; климаморфа; фанерофит; хамефит; гемикриптофит; криптофит; терофит; 
Макарова Ю.В., Головлёв А.А., Прохорова Н.В. 03.02.00 - общая биология Таксономическая и биоморфологическая структура флоры сосудистых растений..

древесные растения; полудревесные растения; травянистые растения; вегетативная подвижность биоморфы; аборигенные виды; адвентивные виды; гора Кузнецова; Сокольи горы; Волжский район; Самарская область.

\section{Введение}

Гора Кузнецова - малоизученный физико-географический объект Самарской области. Несмотря на близкое расположение Кузнецовой горы к территории г. Самары, флора и растительность этого возвышенного массива прежде специально не изучались. В настоящей статье предпринята первая попытка исследования флоры горы Кузнецова в таксономическом и биоморфологическом аспектах.

\section{объект и методика исследования}

Возвышенный массив с горой Кузнецова (абсолютная высота 236 м) является составной частью орографической системы Сокольих гор и располагается в левобережной северной части Волжского муниципального района Самарской области. На северозападе и севере возвышенный массив Кузнецовой горы ограничивается оврагом, известным в прошлом под названием «Угольный барак», и грейдерной автомобильной дорогой. С востока условной границей является отрезок асфальтированного шоссе между пос. Управленческий и бывшим пос. Горным (от места соединения асфальтированного шоссе с грейдерной автомобильной дорогой и до грунтовой дороги, ведущей к лыжной базе «Динамо»). Условной границей возвышенного массива на юге служит грунтовая дорога, ведущая к лыжной базе «Динамо» и пос. Южному. С запада к горе Кузнецова примыкает территория поселков Южный и Красная Глинка (ceлитебные площади, дачные участки, гаражи и другие антропогенные объекты) [1;2].

В пределах обозначенного выше пространства в вегетационные периоды 2015-2017 гг. авторами были совершены полевые маршруты с целью исследования флористического разнообразия. На основе по- лученных данных был составлен предварительный конспект флоры сосудистых растений и осуществлен ее таксономический и биоморфологический анализ. Латинские названия таксонов в статье даны по П.Ф. Маевскому [3], сведения о видах взяты из работ Т.И. Плаксиной [4], Н.М. Матвеева [5], Н.С. Ракова с соавт. [6] и В.В. Тарасова [7].

\section{Результаты исследования и их обсуждение}

Результаты проведенных на горе Кузнецова флористических исследований представлены в табл. 1. Как следует из этой таблицы, основу флоры составляют представители отдела Spermatophyta (258 видов, или 96,7\% от числа установленных видов), среди которых преобладают покрытосеменные (257 видов, 96,3\%), двудольные растения (228 видов, 85,4\%). Полученные данные подчеркивают принадлежность флоры Кузнецовой горы к флорам умеренных широт Голарктики. Два других отдела малочисленны. К отделу Equisetophyta относится 1 семейство - Equisetaceae, представленное 1 родом и 3 видами: Equisetum arvense L., E. hyemale L., E. pratense Ehrh. Отдел Polypodiophyta насчитывает 4 семейства (Onocleaceae, Woodsiaceae, Dryopteridaceae, Dennstaedtiaceae), в которых 5 родов и 6 видов: Matteuccia struthiopteris (L.) Todaro, Athyrium filix-femina (L.) Roth, Cystopteris fragilis (L.) Bernh., Dryopteris carthusiana (Vill.) H.P. Fuchs, D. filix-mas (L.) Schott, Pteridium aquilinum (L.) Kuhn s.l. В целом на долю споровых растений приходится $3,3 \%$ от видового разнообразия сосудистых растений горы Кузнецова. Вместе с тем они являются важным компонентом лесных фитоценозов и на отдельных участках выступают фоновыми видами травостоя.

Таблица 1 - Соотношение основных систематических групп во флоре сосудистых растений горы Кузнецова

\begin{tabular}{|c|c|c|c|c|c|c|c|c|}
\hline \multirow{3}{*}{ Систематическая группа } & \multicolumn{8}{|c|}{ Количество } \\
\hline & \multicolumn{2}{|c|}{ порядков } & \multicolumn{2}{|c|}{ семейств } & \multicolumn{2}{|c|}{ родов } & \multicolumn{2}{|c|}{ видов } \\
\hline & абс. & отн., \% & абс. & отн., \% & абс. & отн., \% & абс. & отн., \% \\
\hline $\begin{array}{l}\text { Отдел Equisetophyta } \\
\text { (Класс Equisetopsida) }\end{array}$ & 1 & 3,8 & 1 & 1,6 & 1 & 0,5 & 3 & 1,1 \\
\hline $\begin{array}{l}\text { Отдел Polypodiophyta } \\
\text { (Класс Polypodiopsida) }\end{array}$ & 1 & 3,8 & 4 & 6,3 & 5 & 2,7 & 6 & 2,2 \\
\hline Отдел Spermatophyta & 24 & 92,4 & 58 & 92,1 & 184 & 96,8 & 258 & 96,7 \\
\hline Класс Pinopsida & 1 & 3,8 & 1 & 1,6 & 1 & 0,5 & 1 & 0,4 \\
\hline $\begin{array}{l}\text { Класс Angiospermae, } \\
\text { в том числе: }\end{array}$ & 23 & 88,6 & 57 & 90,5 & 183 & 96,3 & 257 & 96,3 \\
\hline Dicotyledones & 21 & 80,8 & 47 & 74,6 & 160 & 84,2 & 228 & 85,4 \\
\hline Подкласс Magnoliidae & 1 & 3,8 & 1 & 1,6 & 2 & 1,1 & 2 & 0,7 \\
\hline Подкласс Ranunculidae & 1 & 3,8 & 2 & 3,2 & 9 & 4,7 & 11 & 4,1 \\
\hline Подкласс Rosidae & 13 & 50,1 & 27 & 42,8 & 70 & 36,8 & 103 & 38,7 \\
\hline Подкласс Asteridae & 6 & 23,1 & 17 & 27,0 & 79 & 41,6 & 112 & 41,9 \\
\hline $\begin{array}{l}\text { Monocotyledones } \\
\text { (Подкласc Liliidae) }\end{array}$ & 2 & 7,7 & 10 & 15,9 & 23 & 12,1 & 29 & 10,9 \\
\hline Всего: & 26 & 100,0 & 63 & 100,0 & 190 & 100,0 & 267 & 100,0 \\
\hline
\end{tabular}

Ведущими по числу видов являются 10 из 63 семейств, в состав которых входят 162 вида $(60,6 \%)$ (табл. 2). Первые 3 семейства содержат 84 вида $(31,4 \%)$, первые 5 семейств - 114 видов $(42,6 \%)$.

Первую позицию в спектре занимает сем. Compositae (44 вида, 16,5\%), как и повсюду в умеренных широтах Голарктики (табл. 2). Вторая и третья стро- ки приходятся на сем. Leguminosae (22 вида, 8,2\%) и Rosaceae (18 видов, 6,7\%). Это сближает изучаемую флору с расположенной по соседству флорой западной части Сокольих гор (включая флору УстьСокского карьера), а также находит отражение в семейственных флористических спектрах ряда лесостепных регионов Российской Федерации (табл. 3). 
Макарова Ю.В., Головлёв А.А., Прохорова Н.В.

Таксономическая и биоморфологическая структура флоры сосудистых растений..

03.02.00 - общая биология

Таблица 2 - Ведущие по числу видов семейства во флоре сосудистых растений горы Кузнецова

\begin{tabular}{|l|r|r|c|}
\hline \multirow{2}{*}{\multicolumn{1}{|c|}{ Семейство }} & \multicolumn{2}{|c|}{ Число видов } & \multirow{2}{*}{ Позиция } \\
\cline { 2 - 3 } & абс. & отн., $\%$ & \\
\hline Compositae & 44 & 16,5 & I \\
\hline Leguminosae & 22 & 8,2 & II \\
\hline Rosaceae & 18 & 6,7 & III \\
\hline Labiatae & 16 & 6,0 & IV \\
\hline Gramineae & 14 & 5,2 & V \\
\hline Umbelliferae & 12 & 4,5 & VI \\
\hline Cruciferae & 11 & 4,1 & VII \\
\hline Boraginaceae & 9 & 3,4 & VIII \\
\hline Scrophulariaceae & 8 & 3,0 & IX-X \\
\hline Ranunculaceae & 8 & 3,0 & IX-X \\
\hline \multicolumn{1}{|c|}{ Bceго: } & 162 & 60,6 & \\
\hline
\end{tabular}

Сравнительно низкое положение сем. Gramineae, вероятнее всего, связано с недостаточной его изученностью на горе Кузнецова. Высокие позиции сем. Labiatae, Cruciferae, Boraginaceae и Scrophulariaceae отражают ослабление зональных черт флоры в связи с аридизацией климата в северном полушарии в конце XX - начале XXI в., а также служат проявлением возрастающей антропогенной нагрузки. Существен- ное видовое разнообразие в сем. Umbelliferae и Ranunculaceae указывает на значительную лесопокрытость изучаемой территории.

В остальных 53 семействах сосредоточено 105 видов (39,4\% от общего числа видов). В сем. Caryophyllaceae 7 видов. По 4 вида содержат 6 семейств: Polygonaceae, Chenopodiaceae, Violaceae, Campanulaceae, Rubiaceae, Cyperaceae. По 3 вида находятся в 7 семействах: Equisetaceae, Papaveraceae, Geraniaceae, Onagraceae, Ulmaceae, Aceraceae, Convallariaceae. По 2 вида - в 14 семействах: Woodsiaceae, Dryopteridaceae, Aristolochiaceae, Rhamnaceae, Betulaceae, Cucurbitaceae, Salicaceae, Euphorbiaceae, Primulaceae, Dipsacaceae, Convolvulaceae, Oleaceae, Plantaginaceae, Liliaceae. К числу моновидовых относятся 25 семейств: Onocleaceae, Dennstaedtiaceae, Pinaceae, Amaranthaceae, Vitaceae, Lythraceae, Cannabaceae, Urticaceae, Fagaceae, Celastraceae, Linaceae, Hypericaceae, Tiliaceae, Malvaceae, Balsaminaceae, Viburnaceae, Caprifoliaceae, Solanaceae, Apocynaceae, Melanthiaceae, Trilliaceae, Asparagaceae, Orchidaceae, Typhaceae, Juncaceae. Большое количество малочисленных семейств $(82,5 \%)$ свидетельствует о гетерогенности изучаемой локальной флоры.

Таблица 3 - Головные части семейственных флористических спектров горы Кузнецова и некоторых регионов Российской Федерации

\begin{tabular}{|c|c|c|c|c|c|c|}
\hline $\begin{array}{c}\text { Гора } \\
\text { Кузнецова }\end{array}$ & $\begin{array}{c}\text { Западная часть } \\
\text { Сокольих гор [8] }\end{array}$ & $\begin{array}{c}\text { Усть-Сокский } \\
\text { карьер [9] }\end{array}$ & $\begin{array}{c}\text { Самарская } \\
\text { Лука [10] }\end{array}$ & $\begin{array}{c}\text { Самарская } \\
\text { область [10] }\end{array}$ & $\begin{array}{c}\text { Волго-Уральский } \\
\text { регион [10] }\end{array}$ & $\begin{array}{c}\text { Средняя } \\
\text { Россия [11] }\end{array}$ \\
\hline Comp. & Comp. & Comp. & Comp. & Comp. & Comp. & Comp. \\
\hline Leg. & Ros. & Leg. = Ros. & Gram. & Gram. & Gram. & Gram. \\
\hline Ros. & Leg. & Salic. & Ros. & Leg. & Leg. & Leg. \\
\hline Lab. & Crucif. = Lil. & Gram. = Scroph. & Crucif. & Ros. & Crucif. & Cyp. \\
\hline Gram. & Salic. = Scroph. & Crucif. & Car. & Crucif. & Cyp. & Ros. \\
\hline Umb. & Gram. = Ran. & Polyg. $=$ Orch. & Leg. = Lab. & Cyp. & Car. & Crucif. \\
\hline Crucif. & Lab. & - & Cyp. & Lab. & Ros. & Car. \\
\hline
\end{tabular}

Примечание. Car. - Caryophyllaceae, Comp. - Compositae, Crucif. - Cruciferae, Cyp. - Cyperaceae, Gram. Gramineae, Lab. - Labiatae, Leg. - Leguminosae, Lil. - Liliaceae, Orch. - Orchidaceae, Polyg. - Polygonaceae, Ran. - Ranunculaceae, Ros. - Rosaceae, Salic. - Salicaceae, Scroph. - Scrophulariaceae, Umb. - Umbelliferae.

Ведущими по числу родов являются 10 семейств (табл. 4). В первых трех семействах - Compositae, Rosaceae, Labiatae - находится 56 родов $(29,5 \%$ от общего числа родов). В первых пяти семейства Compositae, Rosaceae, Labiatae, Gramineae, Umbelliferae - 79 родов $(41,6 \%)$.

Таблица 4 - Ведущие по числу родов семейства во флоре сосудистых растений горы Кузнецова

\begin{tabular}{|l|r|r|c|}
\hline \multirow{2}{*}{\multicolumn{1}{|c|}{ Семейство }} & \multicolumn{2}{|c|}{ Число родов } & \multirow{2}{*}{ Позиция } \\
\cline { 2 - 3 } & абс. & отн., $\%$ & \\
\hline Compositae & 29 & 15,3 & I \\
\hline Rosaceae & 14 & 7,4 & II \\
\hline Labiatae & 13 & 6,8 & III \\
\hline Gramineae & 12 & 6,3 & IV \\
\hline Umbelliferae & 11 & 5,8 & V-VI \\
\hline Cruciferae & 11 & 5,8 & V-VI \\
\hline Leguminosae & 8 & 4,2 & VII-VIII \\
\hline Boraginaceae & 6 & 4,2 & VII-VIII \\
\hline Ranunculaceae & 6 & 3,2 & IX \\
\hline Caryophyllaceae & 5 & 2,6 & X \\
\hline \multicolumn{1}{|c|}{ Bceго: } & 117 & 61,6 & \\
\hline
\end{tabular}

Следует отметить, что сем. Leguminosae стоит ниже в таблице семейств, ведущих по числу родов (табл. 4), чем в таблице семейств, ведущих по числу видов (табл. 2), а сем. Scrophulariaceae не является ведущим по числу родов (табл. 4). Это свидетельствует о том, что в этих семействах ряд родов представлен двумя и более видами. И напротив, в сем. Rosaceae, Labiatae, Gramineae, Umbelliferae, Cruciferaе и Caryophyllaceae число монотипных родов выше, чем родов, содержащих 2 и более видов.

Родовой коэффициент, представляющий собой отношение общего числа видов к общему числу родов [12], составляет 1,4. Это указывает на достаточную степень систематического разнообразия флоры сосудистых растений горы Кузнецова.

Самым многочисленным является род Trifolium: он содержит 7 видов, что обусловлено включением в его состав рода Amoria. В родах Viola, Campanula, Galium и Carex по 4 вида. Роды Equisetum, Geranium, Lathyrus, Medicago, Vicia, Potentilla, Ulmus, Acer, Artemisia, Carduus, Crepis, Veronica, Leonurus заключают по 3 вида. На долю родов, ведущих по числу видов, приходится 9,5\% от родового богатства флоры 
Макарова Ю.В., Головлёв А.А., Прохорова Н.В.

горы Кузнецова. Помимо перечисленных, 33 рода $(17,4 \%)$ содержат по 2 вида. Среди них Dryopteris, Anemone, Ranunculus, Chenopodium, Silene, Stellaria, Epilobium, Astragalus, Melilotus, Fragaria, Rubus, Populus, Euphorbia, Lysimachia, Angelica, Achillea, Ambrosia, Arctium, Centaurea, Cirsium, Erigeron, Inula, Senecio, Tanacetum, Pulmonaria, Fraxinus, Melampyrum, Verbascum, Plantago, Stachys, Polygonatum, Brachypodium, Setaria. Остальные 139 родов $(73,1 \%)$ являются одновидовыми.

В процессе эволюции каждый растительный вид приобрел определенный внешний облик. Последний сформировался под влиянием комплекса разнообразных, совместно действующих абиотических и биотических факторов окружающей природной среды и получил название «жизненная форма» [13]. Особенности жизненной формы (биоморфы) определяют место видовой ценопопуляции растения в морфологической (надземные и подземные ярусы, синузии, микрогруппировки) и функциональной (эдификаторы, субэдификаторы, ассектаторы) структуре фитоценозов.

Анализ флоры сосудистых растений горы Кузнецова по системе жизненных форм К. Раункиера [14] характеризует ее как гемикриптофитную. Гемикриптофитами являются 148 видов $(55,4 \%$ от общего числа установленных видов). Преобладание гемикриптофитов является характерной чертой естественных растительных сообществ в умеренных широтах.

Вторую позицию с большим отрывом от гемикриптофитов занимают фанерофиты (30 видов, $11,2 \%)$. Среди фанерофитов лидируют мезофанерофиты (14 видов, 5,2\%): Pinus sylvestris L., Padus avium Mill., Pyrus communis L., Ulmus glabra Huds., U. laevis Pall., U. pumila L., Quercus robur L., Betula pendula Roth, Populus alba L., P. tremula L., Tilia cordata Mill., Acer platanoides L., Fraxinus lanceolata Borkh., F. pennsylvanica Marsh. За мезофанерофитами следуют микрофанерофиты (9 видов, 3,4\%): Crataegus volgensis Pojark., Malus sylvestris (L.) Mill., Sorbus aucuparia L., Frangula alnus Mill., Rhamnus cathartica L., Corylus avellana L., Acer negundo L., A. tataricum L., Viburnum opulus L. Нанофанерофитами являются 7 видов (2,6\%): Caragana frutex (L.) C. Koch, Cerasus fruticosa Pallas, Rosa cinnamomea L., Rubus idaeus L., Euonymus verrucosa Scop., Lonicera xylosteum L., Parthenocissus quinquefolia (L.) Planch. Среди фанерофитов 20\% являются адвентивными видами, распространение плодов и семян которых происходит путем зоохории и анемохории: Ulmus pumila L., Fraxinus lanceolata Borkh., F. pennsylvanica Marsh., Acer negundo L., Parthenocissus quinquefolia (L.) Planch., Pyrus communis L.

Терофиты близки к фанерофитам по численности (29 видов, 10,9\%). При этом аборигенными видами являются только шесть (20,7\% от суммы терофитов): Persicaria maculosa Gray, Lapsana communis L., Melampyrum argyrocomum Fisch. ex Steud., M. arvense L., Acinos arvensis L., Galium aparine L. Остальные терофиты (23 вида, 79,3\% от общего числа терофитов) - это адвентивные виды. Среди последних Consolida regalis S.F. Gray, Fallopia convolvulus (L.) Á. Löve, Polygonum aviculare L., Amaranthus retroflexus L., Atriplex patula L., Chenopodium album L., Ch. hybridum L., Kochia scoparia (L.) Schrad., Echino- cystis lobata Torr. et A. Gray, Viola arvensis Murr., Linum usitatissimum L., Thlaspi arvense L., Impatiens parviflora DC., Ambrosia artemisiifolia L., A. trifida L., Anthemis arvensis L., Bidens frondosa L., Cyclachaena xanthiifolia (Nutt.) Fresen., Erigeron canadensis L., Xanthium strumarium L., Stachys annua (L.) L., Setaria pumila (Poir.) Roem. et Schult., S. viridis (L.) Beauv. s.l. Большинство терофитов является типичными видами открытых антропогенно нарушенных местообитаний.

Четвертую позицию занимают криптофиты (25 видов, 9,4\%). Это виды, обитающие преимущественно в лесах и на опушках: Corydalis solida (L.) Clairv., Lathyrus vernus (L.) Bernh., Galium odoratum (L.) Scop., Paris quadrifolia L., Convallaria majalis L., Polygonatum multiflorum (L.) All., Epipactis helleborine (L.) Crantz, Melica nutans L., Pteridium aquilinum (L.) Kuhn s.1., Polygonatum odoratum (Mill.) Druce, Tulipa biebersteiniana Schult. et Schult. fil., Equisetum pratense Ehrh., Chaerophyllum bulbosum L., Calamagrostis epigeios (L.) Roth, Cirsium incanum (S.G. Gmel.) Fisch., Veratrum lobelianum Bernh., Bromopsis inermis (Leyss.) Holub. Сходную климаморфу имеют: прибрежно-водный Typha latifolia L., болотно-луговой Myosoton aquaticum (L.) Moench, лугово-степной Asparagus officinalis L., прибрежнолугово-сорный Equisetum arvense L., сорно-луговые Tussilago farfara L. и Elytrigia repens (L.) Nevski, copный Convolvulus arvensis L. Среди перечисленных видов 1 гелофит (Typha latifolia L.), остальные - геофиты.

Терофиты-гемикриптофиты занимают пятую позицию (22 вида, 8,2\%). Во флоре горы Кузнецова они представлены однолетниками, двулетниками или травянистыми монокарпическими многолетниками. Аборигенными терофитами-гемикриптофитами являются 13 видов (59,1\% от общего числа терофитовгемикриптофитов): Stellaria media (L.) Vill., Geranium robertianum L., Medicago lupulina L., Viola tricolor L., Cardamine impatiens L., Rorippa palustris (L.) Bess., Torilis japonica (Houtt.) DC., Crepis biennis L., C. sibirica L., C. tectorum L., Tripleurospermum inodorum (L.) Sch. Bip., Myosotis arvensis (L.) Hill., Leonurus marrubiastrum L. К числу адвентивных терофитов-гемикриптофитов относятся 9 видов (40,9\%): Viola arvensis Murr., Capsella bursa-pastoris (L.) Medik., Lepidium densiflorum Schrad., Sisymbrium loeselii L., Lactuca serriola L., Senecio vulgaris L., Lappula squarrosa (Retz.) Dumort., Dracocephalum thymiflorum L., Bromus squarrosus L. s.l.

Хамефиты (11 видов, 4,1\%) расположились на шестом месте. Это Equisetum hyemale L., Asarum europaeum L., Stellaria holostea L., Medicago sativa L., Trifolium repens L., Rubus caesius L., Lysimachia nummularia L., Artemisia absinthium L., A. campestris L., Veronica chamaedrys L., V. teucrium L. Для абсолютного большинства хамефитов (Equisetum hyemale L., Asarum europaeum L., Stellaria holostea L., Rubus caesius L., Lysimachia nummularia L., Veronica chamaedrys L., V. teucrium L.) лесные и связанные с ними опушечные биотопы являются основными местами обитания.

Замыкают биологический спектр виды, относящиеся к группам гемикриптофитов-хамефитов ( $\mathrm{Ne}$ peta pannonica L.) и криптофитов-гемикриптофитов (Scrophularia nodosa L.). 
Таким образом, 55,4\% видов сосудистых растений, произрастающих на горе Кузнецова, можно считать устойчивыми к действию неблагоприятных климатических и погодных условий. Эти виды являются гемикриптофитами. Еще $28,9 \%$ видов (криптофиты-гемикриптофиты, криптофиты, терофиты-гемикриптофиты, терофиты) являются повышенноустойчивыми и сверхустойчивыми [15]. Вместе с тем высокая степень сомкнутости древостоя на большей части площади горы Кузнецова существенно повышает устойчивость фанерофитов, хамефитов и гемикриптофитов-хамефитов, чувствительных к колебаниям погодных условий. К числу последних климаморф относится $15,7 \%$ видов.

Согласно системе жизненных форм И.Г. Серебрякова [16; 17] и Т.И. Серебряковой [18], во флоре возвышенного массива с горой Кузнецова преобладают травянистые растения (236 видов, 88,4\%). Травянистым растениям существенно уступают по численности древесные (29 видов, 10,8\%) и полудревесные растения (2 вида, $0,8 \%$ ) (табл. 5).

Среди травянистых растений наиболее многочисленны многолетние поликарпические травы (162 вида, $60,7 \%$ от общего числа видов). Абсолютное большинство поликарпических трав является короткокорневищными, длиннокорневищными (по 43 вида, по 16,2\%) и стержнекорневыми (39 видов, 14,6\%) (табл. 5). Высокий процент короткокорневищных, длиннокорневищных и стержнекорневых поликарпиков ( $47 \%$ от суммы видов) свидетельствует о повышенной рыхлости и хорошей аэрации верхнего корнеобитаемого слоя почв на большей части площади горы Кузнецова. Кроме перечисленных биоморф, среди травянистых поликарпиков встречаются кистекорневые, длиннокорневищно-стержнекорневые, дерновинные, короткокорневищно-дерновинные, длиннокорневищно-корнеотпрысковые, корнеотпрысковые, столонные, клубневые, луковичные и лианы травянистые, составляющие в сумме 37 видов, или $13,7 \%$.

Группа травянистых монокарпиков представлена 74 видами (27,7\% от суммы видов) (табл. 5). Внутри нее доминируют однолетники (30 видов, $11,2 \%$ ), за которыми следуют однолетники-малолетники (16 видов, $6,1 \%)$, малолетники (14 видов, 5,2\%), однолетники, малолетники или монокарпические многолетники (14 видов, 5,2\%).

К числу древесных растений относятся 29 видов (10,8\%) (табл. 5). В первую очередь это деревья (5,2\%): Acer platanoides L., A. negundo L., Tilia cordata Mill., Quercus robur L., Ulmus glabra Huds., U. laevis Pall., U. pumila L., Betula pendula Roth, Populus alba L., P. tremula L., Fraxinus lanceolata Borkh., F. pennsylvanica Marsh., Pinus sylvestris L., Pyrus communis L. За ними следуют кустарники-деревья Padus avium Mill., Sorbus aucuparia L., Frangula alnus Mill., Acer tataricum L., Malus sylvestris (L.) Mill., Crataegus volgensis Pojark. (2,6\%), кустарники Corylus avellana L., Euonymus verrucosa Scop., Viburnum opulus L., Lonicera xylosteum L., Rhamnus cathartica L., Rosa cinnamomea L., Caragana frutex (L.) C. Koch, Cerasus fruticosa Pallas $(2,6 \%)$ и кустарникполукустарник Rubus idaeus L. $(0,4 \%)$.
Полудревесные растения представлены полукустарником Rubus caesius L. и деревянистой лианой Parthenocissus quinquefolia (L.) Planch. (табл. 5).

таблица 5 - Спектр жизненных форм по системе И.Г. Серебрякова и Т.И. Серебряковой во флоре сосудистых растений горы Кузнецова

\begin{tabular}{|c|c|c|}
\hline \multirow{2}{*}{ Биоморфа } & \multicolumn{2}{|c|}{ Число видов } \\
\hline & абс. & отн., \% \\
\hline А. Древесные растения & 29 & 10,8 \\
\hline Деревья & 14 & 5,2 \\
\hline Деревья или кустарники & 7 & 2,6 \\
\hline Кустарники & 7 & 2,6 \\
\hline Кустарники или полукустарники & 1 & 0,4 \\
\hline Б. Полудревесные растения & 2 & 0,8 \\
\hline Полукустарники & 1 & 0,4 \\
\hline Лианы полудревесные & 1 & 0,4 \\
\hline В. Травянистые растения & 236 & 88,4 \\
\hline а) Монокарпики & 74 & 27,7 \\
\hline Однолетники & 30 & 11,2 \\
\hline Однолетники или малолетники & 16 & 6,1 \\
\hline Малолетники & 14 & 5,2 \\
\hline $\begin{array}{l}\text { Однолетники, малолетники } \\
\text { или многолетники, в том числе: }\end{array}$ & 14 & 5,2 \\
\hline - стержнекорневые & 12 & 4,5 \\
\hline - кистекорневые & 1 & 0,4 \\
\hline - корневищные & 1 & 0,4 \\
\hline б) Поликарпики & 162 & 60,7 \\
\hline Стержнекорневые & 39 & 14,6 \\
\hline Кистекорневые & 1 & 0,4 \\
\hline Длиннокорневищные & 43 & 16,2 \\
\hline $\begin{array}{l}\text { Длиннокорневищно- } \\
\text { стержнекорневые }\end{array}$ & 1 & 0,4 \\
\hline Дерновинные, в том числе: & 4 & 1,4 \\
\hline - рыхлодерновинные & 2 & 0,7 \\
\hline - плотнодерновинные & 2 & 0,7 \\
\hline Короткокорневищные & 43 & 16,2 \\
\hline $\begin{array}{l}\text { Короткокорневищно- } \\
\text { дерновинные, в том числе: }\end{array}$ & 4 & 1,4 \\
\hline $\begin{array}{l}\text { - короткокорневищно- } \\
\text { рыхлодерновинные }\end{array}$ & 1 & 0,4 \\
\hline $\begin{array}{c}\text { - короткокорневищно- } \\
\text { плотнодерновинные }\end{array}$ & 3 & 1,1 \\
\hline $\begin{array}{l}\text { Длиннокорневищно- } \\
\text { корнеотпрысковые }\end{array}$ & 2 & 0,7 \\
\hline Корнеотпрысковые & 8 & 3,0 \\
\hline Столонные & 2 & 0,7 \\
\hline Клубневые & 7 & 2,6 \\
\hline Луковичные & 2 & 0,7 \\
\hline Лианы травянистые & 6 & 2,3 \\
\hline Всего: & 267 & 100,0 \\
\hline
\end{tabular}

На горе Кузнецова в древесном ярусе лесов преобладают Acer platanoides L., Tilia cordata Mill., Ulmus laevis Pall. и U. glabra Huds. Основная лесообразующая порода восточноевропейских лиственных лесов - Quercus robur L. - в древостое не доминирует. Отдельные, небольшие по площади участки заняты осиновыми (Populus tremula L.) и березовыми (Betula pendula Roth) насаждениями. На скальных участках западной и юго-западной ориентации Кузнецовой горы фрагментарно встречается Pinus sylvestris $\mathrm{L}$. 
Макарова Ю.В., Головлёв А.А., Прохорова Н.В.

В подлеске лиственных лесов господствуют Corylus avellana L., Euonymus verrucosa Scop., Frangula alnus Mill., Viburnum opulus L., Rubus caesius L., в смешанных лесах - Caragana frutex (L.) C. Koch, Cerasus fruticosa Pallas, Euonymus verrucosa Scop. Примесными видами являются Padus avium Mill., Sorbus aucuparia L., Rhamnus cathartica L., Lonicera xylosteum L. Вдоль лесных дорог и на опушках среди полукустарников, кустарников и невысоких деревьев преимущественное развитие получают Rubus idaeus L., Rosa cinnamomea L., Acer tataricum L.

Важной характеристикой биоморфы является вегетативная подвижность [19], которая проявляется в способности биоморфы к вегетативному размножению, разрастанию, «захвату» пространства. По шкале вегетативной подвижности Н.М. Матвеева [15] преобладающее число видов - $149(55,8 \%)$ - являются вегетативно неподвижными. Группа вегетативно малоподвижных представлена 56 видами $(21,0 \%)$, вегетативно среднеподвижных - 8 видами $(3,0 \%)$, вегетативно сверхподвижных - 54 видами $(20,2 \%)$. Следовательно, только $23,2 \%$ видов от состава анализируемой флоры обладают средней и высокой вегетативной подвижностью. Остальные 76,8\% являются вегетативно неподвижными и малоподвижными видами, для которых генеративный тип размножения основной.

В составе флоры сосудистых растений Кузнецовой горы установлено 10 видов, включенных в региональную Красную книгу: Matteuccia struthiopteris (L.) Todaro, Athyrium filix-femina (L.) Roth, Anemone altaica Fisch. ex C.A. Mey., Crataegus volgensis Pojark., Populus alba L., Bupleurum aureum (Hoffm.) Fisch. ex Hoffm., Laser trilobum (L.) Borkh., Campanula latifolia L., Tulipa biebersteiniana Schult. et Schult. fil., Epipactis helleborine (L.) Crantz. Еще 2 вида Aconitum septentrionale Koelle и Corydalis solida (L.) Clairv. - относятся к числу мониторинговых на территории Самарской области [20].

\section{Выводы}

К настоящему времени на горе Кузнецова установлено 267 видов сосудистых растений, принадлежащих к 190 родам, 63 семействам, 26 порядкам, 4 классам (Equisetopsida, Polypodiopsida, Pinopsida, Angiospermae) и 3 отделам (Equisetophyta, Polypodiophyta, Spermatophyta). Среди биоморф доминируют поликарпические короткокорневищные, длиннокорневищные и стержнекорневые травы $(47,0 \%)$. У значительной части выявленных видов $(76,8 \%)$ генеративное размножение преобладает над вегетативным. Высокое процентное содержание гемикриптофитов, криптофитов, терофитов и их смежных форм (84,3\%) позволяет говорить о флоре сосудистых растений горы Кузнецова как об устойчивой к воздействию неблагоприятных климатических и погодных условий региона.

\section{Список литературы:}

1. Куйбышев. План-схема. Масштаб 1: 25000. Лист 2. М.: Главное управление геодезии и картографии при Совете министров СССР, 1982.

2. Самарская область. Административная карта. Масштаб 1: 380 000. Самара: ООО «Карта +», 2017.
3. Маевский П.Ф. Флора средней полосы европейской части России. 11-е изд. М.: Товарищество научных изданий КМК, 2014. 635 с.

4. Плаксина Т.И. Конспект флоры Волго-Уральского региона. Самара: Изд-во «Самарский университет», 2001. $388 \mathrm{c}$.

5. Матвеев Н.М. Биоэкологический анализ флоры и растительности (на примере лесостепной и степной зоны). Самара: Изд-во «Самарский университет», 2006. $311 \mathrm{c}$.

6. Раков Н.С., Саксонов С.В., Сенатор С.А., Васюков В.М. Сосудистые растения Ульяновской области. Флора Волжского бассейна. Т. ІІ. Тольятти: Кассандра, 2014. 295 с.

7. Тарасов В.В. Флора Дніпропетровської і Запорізької областей. Судинні рослини 3 їх біологоекологічною характеристикою. Днепропетровск: Видво Дніпропетр. ун-ту, 2005. 254 с.

8. Макарова Ю.В., Прохорова Н.В., Головлёв А.А., Куликова М.В. К флоре западной части Сокольих гор // Вестник Самарского государственного университета. Естественнонаучная серия. 2012. № 9 (100). C. 191-199.

9. Самыкина М.В. Процессы ренатурализации техногенных ландшафтов карбонатных карьеров на примере Усть-Сокского (Западного) карьера в Самарской области: дис. ... канд. биол. наук. Тольятти, 2016. 224 c.

10. Иванова А.В. Таксономическая характеристика флоры Самарской Луки // Известия Самарского научного центра РАН. 2010. Т. 12 (33), № 1 (1). C. $31-41$.

11. Бакин О.В., Рогова Т.В., Ситников А.П. Сосудистые растения Татарстана. Казань: Изд-во Казан. ун-та, 2000. 496 с.

12. Шмидт В.М. Систематические методы в сравнительной флористике. Л.: Наука, 1980. 180 с.

13. Warming E. Lehrbuch der okologischen Pflanzengeographie: eine Einfuhrung in die Kenntnis der Pflanzenvereine. Berlin: Gebrüder Borntraeger, 1896. $412 \mathrm{p}$.

14. Raunkiaer K. Types biologiques pour la geographiy botanique // Forhandl. Kgl. Dansk. Vidensk. Selskab. V. 5. 1905. P. 347-437.

15. Матвеев Н.М. Основы степного лесоведения профессора А.Л. Бельгарда и их современная интерпретация: учеб. пособие. Самара: Изд-во «Самарский университет», 2012. $128 \mathrm{c}$.

16. Серебряков И.Г. Экологическая морфология растений: жизненные формы покрытосеменных и хвойных. М.: Высшая школа, 1962. 378 с.

17. Серебряков И.Г. Жизненные формы высших растений и их изучение // Полевая геоботаника. 1964. T. 3. C. 146-205.

18. Серебрякова Т.И. Учение о жизненных формах растений на современном этапе // Итоги науки и техники. Сер. Ботаника. 1972. Т. 1. С. 84-169.

19. Раменский Л.Г. Избранные работы: проблемы и методы изучения растительного покрова. Л.: Наука, 1971.334 с.

20. Красная книга Самарской области. В 2 т. Т. 1. Редкие виды растений, лишайников и грибов / под ред. Г.С. Розенберга, С.В. Саксонова. Тольятти: ИЭВБ РАН, 2007. 372 c. 


\title{
TAXONOMIC AND BIOMORPHOLOGICAL STRUCTURE OF MOUNTAIN KUZNETSOV VASCULAR PLANTS FLORA (SAMARA REGION, VOLZHSKY DISTRICT)
}

(C) 2018

\author{
Makarova Yulia Vladimirovna, candidate of biological sciences, \\ senior lecturer of Ecology, Botany and Nature Protection Department \\ Samara National Research University (Samara, Russian Federation) \\ Golovlyov Aleksey Alekseevich, doctor of geographical sciences, professor of World Economy Department \\ Samara State University of Economics (Samara, Russian Federation) \\ Prokhorova Nataliya Vladimirovna, doctor of biological sciences, \\ professor of Ecology, Botany and Nature Protection Department \\ Samara National Research University (Samara, Russian Federation)
}

Abstract. The presence of 267 vascular plants species from 190 genera, 63 families, 26 orders, 4 classes (Equisetopsida, Polypodiopsida, Pinopsida, Angiospermae) and 3 divisions (Equisetophyta, Polypodiophyta, Spermatophyta) was established for Kuznetsov Mountain. The absolute majority of species belong to Spermatophyta (258 species, 96,7\%), Angiospermae (257 species, 96,3\%), Dicotyledones (228 species, 85,4\%). Vascular spore plants are represented by 9 species belonging to 6 genera (Equisetum, Matteuccia, Athyrium, Cystopteris, Dryopteris, Pteridium), 5 families (Equisetaceae, Onocleaceae, Woodsiaceae, Dryopteridaceae, Dennstaedtiaceae), 2 classes (Equisetopsida, Polypodiopsida) and 2 divisions (Equisetophyta, Polypodiophyta). The leading families according the species diversity are Compositae (44 species, 16,5\%), Leguminosae (22 species, 8,2\%) and Rosaceae (18 species, $6,7 \%$ ). The leading families according the number of genera are Compositae ( 29 genera, 15,3\%), Rosaceae (14 genera, 7,4\%) and Labiatae (13 genera, 6,8\%). The largest number of species is concentrated in the genera Trifolium (7 species), Viola, Campanula, Galium and Carex (4 species each). According to the climamorphic system of K. Raunkiaer, hemicryptophytes predominate in the flora (148 species, 55,4\%). According to the biomorph system I.G. Serebryakov and T.I. Serebryakova - perennial polycarpic short-stemmed, long-rooted, and rod-root grasses $(47,0 \%)$ predominate. $76,8 \%$ of the species are vegetatively still and immobile.

Keywords: flora; vascular plants; taxonomic analysis; biomorphological analysis; life forms; biomorphes; climamorphes; phanerophyte; hamefit; hemicryptophyte; cryptophyte; terophyte; woody plants; half-timbered plants; herbaceous plants; vegetative mobility of biomorph; Aboriginal species; adventive species; Mountain Kuznetsov; Sokolii Mountains; Volzhsky District; Samara Region.

УДК 574.587

Статья поступила в редакцию 01.12.2017

\section{РАСПРЕДЕЛЕНИЕ МЕЙОБЕНТОСА ПО ГРАДИЕНТУ СОЛЕНОСТИ В ЭСТУАРИИ РЕКИ РАЗДОЛЬНОЙ ПРИМОРСКОГО КРАЯ}

Милованкина Александра Александровна, аспирант кафедры экологии Фадеева Наталия Петровна, доктор биологических наук, профессор кафедры экологии Дальневосточный федеральный университет (2. Владивосток, Российская Федерация)

Чертопруд Елена Сергеевна, кандидат биологических наук,

ведущий научный сотрудник кафедры гидробиологии; ведущий инженер лаборатории синэкологии Московский государственный университет имени М.В. Ломоносова (г. Москва, Российская Федераџия); Институт проблем экологии и эволючии имени А.Н. Северцуова РАН (г. Москва, Российская Федерация)

Аннотация. По результатам бентосных съемок эстуария реки Раздольной (Японское море, Амурский залив) прослежено распределение мейобентоса по градиенту солености. Плотность мейобентоса в эстуарии реки Раздольной увеличивалась с ростом показателей солености. Мейобентос представлен 8 таксономическими группами (Nematoda, Copepoda, Ostracoda, Oligochaeta, Mollusca, Amphipoda, Polychaeta и Chironomidae) при доминировании нематод. Большая часть мейобентосных видов представлена морскими эвригалинными видами, встречающимися на всем протяжении эстуария. В мейобентосе в олигогалинной зоне доминируют широко распространенные в эстуариях Дальнего Востока России пресноводные виды Dorylaimus chassanicus, Hofmaenneria gratiosa, Theristus brevisetosus и нематоды рода Paradontophora; в мезогалинной зоне Monhystrella sp., Oncholaimium japonicum, Anoplostoma cuticularia, Daptonema inversum, а также гарпактикоиды Remanea naksanensis, Onychocamptus mohammed, Huntemannia biarticulatus, Halectinosoma sp. На всем протяжении эстуария реки Раздольной состав нематод изменяется по зонам: для пресной воды и олигогалинной зон характерно доминирование нематод рода Paradontophora, а также наличие пресноводных видов (Dorylaimus chassanicus, Hofmaenneria gratiosa, Theristus brevisetosus); для мезогалинной зоны - доминирование Monhystrella sp. и снижение числа пресноводных видов; для эугалинной зоны - доминирование Paracanthonchus macrodon, Oncholaimium paraolium, Sabatieria finitima, Dorylaimopsis peculiaris и S. palmaris. Нематоцены внутренней части эстуарной зоны не отличаются специфическим набором видов и состоят из видов, характерных для сообщества нематод как опресненной, так и морской зон. 